\title{
RADIOLOGICAL ANALYSIS OF BONE TUNNEL POSITION IN ANTERIOR CRUCIATE LIGAMENT RECONSTRUCTION SURGERY: COMPARISON BETWEEN THE OPEN TECHNIQUE AND ARTHROSCOPY VIA AN ANTEROMEDIAL PORTAL
}

Jean Marcel Dambrós ${ }^{1}$, Rodrigo Florêncioº ${ }^{2}$, Osmar Valadão Lopes Júnior ${ }^{3}$, André Kuhn ${ }^{3}$, José Saggin ${ }^{3}$, Leandro de Freitas Spinelli ${ }^{4}$

\begin{abstract}
Objectives: To evaluate and compare bone tunnel positioning in anterior cruciate ligament (ACL) reconstruction surgery using the arthroscopic technique and the open technique consisting of arthrotomy. Method: A comparative retrospective study on 70 patients with ACL lesions was conducted. Thirty-five patients underwent ACL reconstruction by means of the open technique and 35 by means of the arthroscopic technique using an anteromedial portal. All the patients underwent ACL reconstruction using an autologous graft from the middle third of the patellar tendon, fixed using interference screws. The postoperative radiographs were reviewed and the positioning of the femoral tunnel was evaluated using the methods proposed by Harner et al. and Aglietti et al., while the tibial tunnel
\end{abstract}

was assessed using the method proposed by Rauschning and Stäubli. Results: Fifty-four of the patients were male and 16 were female. Their mean age at the time of the procedure was 34 years and 3 months, with a range from 17 to 58 years. The arthroscopic technique was shown to be more accurate than the open technique for positioning both the femoral and the tibial bone tunnels. Conclusions: Radiological analysis on the knees subjected to ACL reconstruction showed that the positioning of both the femoral and the tibial bone tunnels presented less variation when the surgery was performed arthroscopically.

Keywords - Anterior Cruciate Ligament/surgery; Anterior Cruciate Ligament/anatomy \& histology; Anterior Cruciate Ligament/radiography; Anterior Cruciate Ligament/ injuries; Knee; Tendons

\section{INTRODUCTION}

The exact incidence of lesions of the anterior cruciate ligament (ACL) is unknown. However, it has been estimated that 200,000 new lesions occur every year. Approximately 100,000 reconstructions are performed every year in the United States ${ }^{(1)}$.

Currently, ACL reconstruction surgery has become one of the most popular knee surgery procedures. The mean success rate is $90 \%$ in relation to restoration of knee stability and patient satisfaction ${ }^{(2-5)}$. The position of the bone tunnels, and consequently the graft, is considered to be one of the most important factors relating to successful reconstruction ${ }^{(5-8)}$. Correct positioning of the bone tunnels is considered to be the most important intraoperative variable, and is directly influenced by the surgeon ${ }^{(9)}$. The positioning of the bone tunnels has a fundamental role in the tensional behavior of the neoligament during flexion-extension

1 - Orthopedist and Traumatologist at the Institute of Orthopedics and Traumatology - Passo Fundo - RS, Brazil.

2 - Orthopedist and Traumatologist at the Genus Clinic - Cuiabá, MT, Brazil.

3 - Orthopedist and Traumatologist and Preceptor of the Knee Surgery Service - Institute of Orthopedics and Traumatology - Passo Fundo - RS, Brazil.

4 - Orthopedist and Traumatologist - Institute of Orthopedics and Traumatology - Passo Fundo - RS. MSc and PhD from the Federal University of Rio Grande do Sul, Brazil.

Work performed at the Institute of Orthopedics and Traumatology, Passo Fundo, RS.

Correspondence: Osmar Valadão Lopes Júnior - Rua Uruguai, 2.050 - 99010-220 - Passo Fundo, RS, Brasil. E-mail: scjp@iotrs.com.br / ovlopesjr@yahoo.com.br

Work received for publication: May 25, 2010; accepted for publication: October 29, 2010. 
movements. Incorrect positioning results in abnormal tension on the graft and may cause clinical problems such as loss of range of motion, impacting of the graft against the posterior cruciate ligament and intercondylar roof, and recurrent instability ${ }^{(10-12)}$.

ACL reconstruction using an autogenous graft may be done either arthroscopically or via the open route, through arthrotomy, and both of these have historically been considered acceptable ${ }^{(13)}$. The arthroscopic technique using the anteromedial portal presents the advantages that it is easy to manipulate the instruments in the medial portion of the lateral femoral condyle; it is easy to position the tibial tunnel; there is no divergence in placing interference screws when the patellar tendon is used; it is easy to locate the entry points when a double band is used; the tunnel can be made with the knee at $120^{\circ}$, without risk of fracturing the dorsal cortical bone of the femoral condyle; and correct rotation of the insertion of the graft along the femoral axis is easily achieved, given that it runs parallel to the tibial plateau when a flexed position of $120^{\circ}$ is used ${ }^{(14)}$. Some studies have shown that there is no statistical difference between the open and arthroscopic techniques, with regard to the clinical results from assessing joint stability, range of motion and postoperative pain ${ }^{(13,15)}$. Raab et $\mathrm{al}^{(13)}$ found a difference between the two techniques only in relation to the duration of the operation. This was not corroborated by Cameron et $\mathrm{al}^{(15)}$, who did not find differences between the techniques with regard to duration of the operation, range of motion and stability test scores. However, neither of these two studies assessed the positioning of the tunnels in their comparative analyses, with regard to either the open technique or the videoarthroscopic technique.

Several methods for measuring the positioning of the tunnels in reconstruction surgery have been described $^{(8,16,17)}$. Among these, the methods of Harner et $\mathrm{al}^{(16)}$ and Aglietti et al ${ }^{(17)}$ for the femoral tunnel and the method of Stäubli and Rauschning ${ }^{(18)}$ for the tibial tunnel are greatly used.

The present study had the aim of evaluating and comparing the positioning of the bone tunnels in a series of patients who underwent $A C L$ reconstruction surgery using the arthroscopic technique or the open technique with arthrotomy.

\section{MATERIALS AND METHODS}

A comparative retrospective study was conducted on 70 patients who underwent ACL reconstruction surgery, selected randomly from the institution's database. Of these, 35 patients underwent ACL reconstruction using the open route and 35 arthroscopically. All of the patients were operated by two experienced surgeons at the Institute of Orthopedics and Traumatology, Passo Fundo, RS. Each surgeon was responsible for half of the operations in each group. The minimum follow-up was taken to be two years. The patients selected were operated between March 1995 and December 2007, in order to also seek out patients operated using the open technique. The patients' postoperative radiographs were reviewed and the positioning of the bone tunnels was assessed. The positioning of the femoral tunnel was assessed using the methods described by Harner et a ${ }^{(16)}$ and Aglietti et $\mathrm{al}^{(17)}$. The tibial tunnel was assessed using the method described by Rauschning and Stäubli ${ }^{(18)}$.

The method described by Harner et al ${ }^{(16)}$ evaluates the positioning of the femoral tunnel on lateral-view radiographs using measurements of the length of the Blumensaat line as the reference (Figure 1). On the other hand, the method described by Aglietti et al. ${ }^{(17)}$ evaluates the positioning of the femoral tunnel based on the anteroposterior length of the distal femur, measured at the level of the Blumensaat line (Figure 2). To analyze the tibial tunnels, the method described by Rauschning and Stäubli( ${ }^{(18)}$ was used (Figure 3). In this, the positioning is evaluated in relation to the anteroposterior length (sagittal diameter) of the tibial plateau.
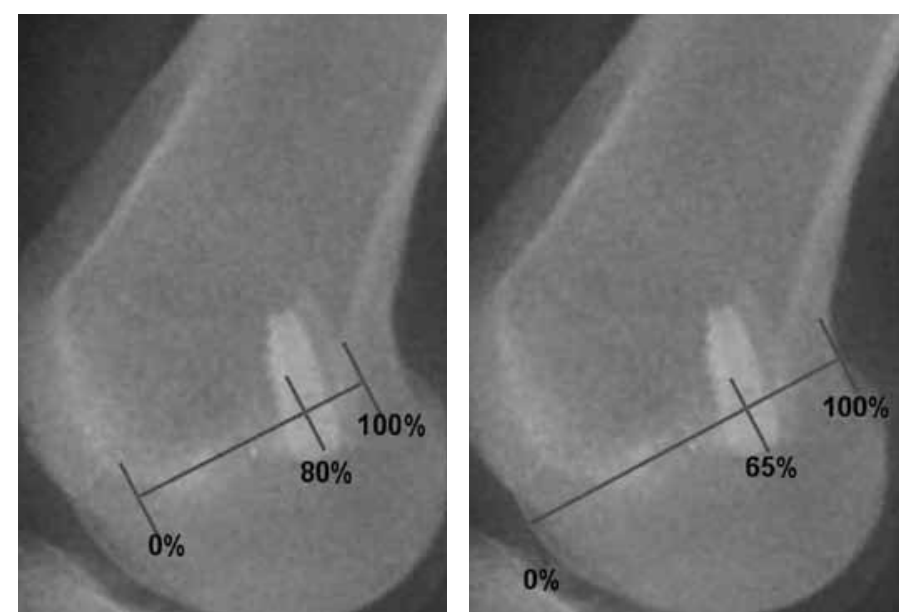

Figure 1 - Method of Harner et al. Figure 2 - Method of Aglietti et al. for verification of the femoral tunnel. for verification of the femoral tunnel. 


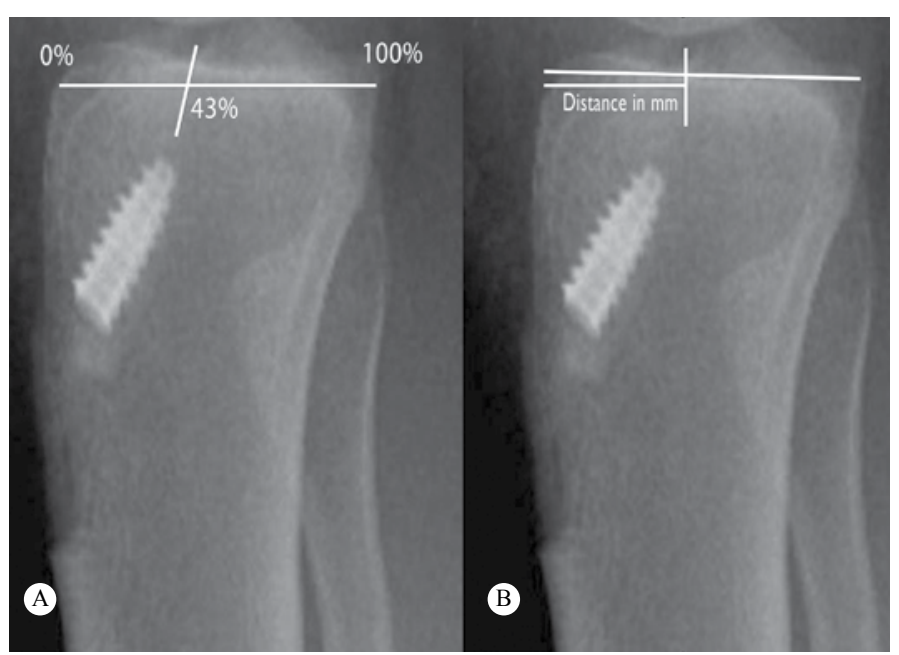

Figure 3 - Method of Rauschning and Stäubli for verification of the tibial tunnel. (a) Measurement as percentage of the anteroposterior length of the tibial plateau; (b) Measurement in millimeters from the anterior margin of the tibial plateau.

\section{SURGICAL TECHNIQUES}

In both techniques, the patients underwent rachianesthesia and were positioned in horizontal dorsal decubitus with a pneumatic tourniquet inflated on the proximal third of the thigh. During the ACL reconstruction, the hip remained flexed at $45^{\circ}$ and the knee remained flexed at approximately $90^{\circ}$.

\section{ACL reconstruction using open technique}

With the knee flexed at $90^{\circ}$, a medial parapatellar incision of approximately $8 \mathrm{~cm}$ was made, with subsequent medial parapatellar arthrotomy, in line with the skin incision. The remaining stumps of the ACL were identified and resected. The location of the ACL insertion in the femur was determined by identifying the remains of the native insertion and, with the knee flexed at $120^{\circ}$, a femoral tunnel of approximately 10 x $30 \mathrm{~mm}$ was made without using a guide. A tibial tunnel of $10 \mathrm{~mm}$ in diameter was made, starting at a point approximately $2 \mathrm{~cm}$ inferiorly to the joint surface and $2 \mathrm{~cm}$ medially to the anterior tuberosity of the tibia. A tibial guide angled at $45^{\circ}-50^{\circ}$ was directed towards the center of the location of ACL insertion in the tibia; the tibial guidewire was positioned; and the tunnel of diameter $10 \mathrm{~mm}$ was constructed under direct viewing. Through the same skin incision, a graft measuring $10 \times 25 \mathrm{~mm}$ was harvested from the central third of the patellar tendon (bone-tendon-bone), with a width of $10 \mathrm{~mm}$ and two bone segments: one tibial and the other, patellar. The graft was then passed through the bone tunnels and fixed using titanium interference screws.

\section{ACL reconstruction using arthroscopic technique}

With the knee flexed at $90^{\circ}$, a median longitudinal incision of approximately $8 \mathrm{~cm}$ was made in the middle region of the patellar tendon. Through this incision, a free graft of approximate width $10 \mathrm{~mm}$ was harvested from the central third of the patellar tendon (bonetendon-bone). Anteromedial and anterolateral portals were made through the same skin incision used for removing the graft. By means of videoarthroscopy, the anatomical insertion locations of the ACL in the femur and tibia were determined and marked out. A femoral guide with an offset of $7 \mathrm{~mm}$ was introduced through the anteromedial portal and positioned more anatomically at the sites previously determined as the locations of the femoral insertion of the ACL. A femoral tunnel of dimensions $10 \times 30 \mathrm{~mm}$ was then made in the knee while it was flexed at $120^{\circ}$. A tibial tunnel of diameter $10 \mathrm{~mm}$ was then made, starting at a point $2 \mathrm{~cm}$ inferiorly to the joint surface and $2 \mathrm{~cm}$ medially to the anterior tuberosity of the tibia. In introducing the tibial guidewire, we used a tibial guide angled at $45^{\circ}$ to $50^{\circ}$, with intra-articular positioning at the center of the tibial insertion of the ACL. The graft was then passed through the bone tunnels and was fixed using titanium interference screws.

After radiological analysis on the postoperative images and measurement of the positioning of the tunnels, the data were analyzed statistically using the $F$ test of analysis of variance.

\section{RESULTS}

There were 54 male patients and 16 female patients. Their mean age at the time of the procedure was 34 years and 3 months, with a range from 17 to 58 years.

The results relating to the positions of the femoral and tibial tunnels using the two techniques are shown in Tables 1 to 3 . Evaluation of the results using the method of Aglietti et al ${ }^{(17)}$ showed that the mean positioning with the arthroscopic technique was $75.46 \%$ ( \pm standard deviation 6.14 ) and with the open technique, $66.40 \%( \pm 8.70)$. Evaluation of the tunnel positioning using the method of Harner et $\mathrm{al}^{(16)}$, sho- 
Table 1 - Position of the femoral tunnel on the lateral-view radiograph of the knee.

\begin{tabular}{c|c|c|c|c|c|c}
\hline & & & & \multicolumn{3}{|c}{$\begin{array}{c}95 \% \text { confidence } \\
\text { interval for } \\
\text { Mean }\end{array}$} \\
\cline { 4 - 7 } & & Technique & Mean & $\begin{array}{c}\text { Standard } \\
\text { deviation }\end{array}$ & $\begin{array}{c}\text { Standard } \\
\text { error }\end{array}$ & \multicolumn{2}{|c}{$\begin{array}{c}\text { Lower } \\
\text { limit }\end{array}$} & $\begin{array}{c}\text { Upper } \\
\text { limit }\end{array}$ \\
\hline $\begin{array}{c}\text { Aglietti } \\
\text { position } \\
(\%)\end{array}$ & Arthroscopic & 75.46 & 6.137 & 1.037 & 73.35 & 77.57 \\
\cline { 3 - 7 } & Open & 66.40 & 8.698 & 1.470 & 63.41 & 69.39 \\
\hline $\begin{array}{c}\text { Harner } \\
\text { position } \\
(\%)\end{array}$ & Arthroscopic & 83.09 & 4.780 & 0.808 & 81.44 & 84.73 \\
\cline { 3 - 7 } & Open & 74.97 & 11.060 & 7.869 & 71.17 & 78.77 \\
\hline
\end{tabular}

Table 2 - Position of the tibial tunnel $(\mathrm{mm})$ on the lateral-view radiograph of the knee.

\begin{tabular}{|c|c|c|c|c|c|c|c|}
\hline \multirow{2}{*}{$\begin{array}{c}\text { Lateral-view } \\
\text { radiograph } \\
\text { of the knee }\end{array}$} & \multirow{2}{*}{ Technique } & \multirow{2}{*}{$\mathbf{N}$} & \multirow{2}{*}{ Mean } & \multirow{2}{*}{$\begin{array}{l}\text { Standard } \\
\text { deviation }\end{array}$} & \multirow{2}{*}{$\begin{array}{c}\text { Standard } \\
\text { error }\end{array}$} & \multicolumn{2}{|c|}{$\begin{array}{c}95 \% \\
\text { confidence } \\
\text { interval for } \\
\text { mean } \\
\end{array}$} \\
\hline & & & & & & $\begin{array}{c}\text { Lower } \\
\text { limit }\end{array}$ & $\begin{array}{l}\text { Lower } \\
\text { limit }\end{array}$ \\
\hline \multirow{2}{*}{$\begin{array}{c}\text { Position of } \\
\text { tunnel } \mathrm{mm} \text { ) }\end{array}$} & Arthroscopic & 35 & 22.0 & 2.351 & 0.397 & 21.19 & 22.81 \\
\hline & Open & 35 & 21.31 & 2.958 & 0.500 & 20.30 & 22.33 \\
\hline
\end{tabular}

Table 3 - Position of the tibial tunnel (\%) on the lateral-view radiograph of the knee.

\begin{tabular}{|c|c|c|c|c|c|c|c|}
\hline \multirow{2}{*}{$\begin{array}{l}\text { Lateral- } \\
\text { view } \\
\text { radiograph } \\
\text { of the } \\
\text { knee }\end{array}$} & \multirow[t]{2}{*}{ Technique } & \multirow[t]{2}{*}{$\mathbf{N}$} & \multirow[t]{2}{*}{ Mean } & \multirow[t]{2}{*}{$\begin{array}{l}\text { Standard } \\
\text { deviation }\end{array}$} & \multirow[t]{2}{*}{$\begin{array}{c}\text { Standard } \\
\text { error }\end{array}$} & \multicolumn{2}{|c|}{\begin{tabular}{|c}
$95 \%$ \\
confidence \\
interval for \\
mean \\
\end{tabular}} \\
\hline & & & & & & $\begin{array}{c}\text { Lower } \\
\text { limit }\end{array}$ & $\begin{array}{l}\text { Lower } \\
\text { limit }\end{array}$ \\
\hline \multirow{2}{*}{$\begin{array}{l}\text { Position of } \\
\text { tunnel (\%) }\end{array}$} & Arthroscopic & 35 & 39.31 & 3.479 & 0.588 & 38.12 & 40.51 \\
\hline & Open & 35 & 36.69 & 4.999 & 0.845 & 34.97 & 38.40 \\
\hline
\end{tabular}

wed that the mean positioning with the arthroscopic technique was $83.09 \%( \pm 4.78)$ and with the open technique, $74.97 \%( \pm 11.06)$.

Through statistical analysis, it was sought to assess whether there was any significant difference in mean position (\%) of the femoral tunnel between the two techniques and for each method of measuring the positioning separately. It was observed that there were statistically significant differences in the analyses on femoral tunnel positioning when the open and arthroscopic techniques were compared using both methods $(p<0.05)$.
Analysis on the radiographs of the tibia by means of the method of Rauschning and Stäubli ${ }^{(18)}$ showed that the mean positioning of the tunnel using the arthroscopic technique was $22 \mathrm{~mm}$ ( \pm standard deviation 2.35) and using the open technique, 21.21 ( \pm 2.96). Regarding the measurement as a percentage of the anteroposterior length of the tibial plateau, the arthroscopic technique presented a mean of $39.31 \%$ $( \pm 3.48)$ and the mean for the open technique was $36.69 \%( \pm 5.00)$.

In relation to the position of the tibial tunnel, it was observed that when the position of the tibial tunnel measured in millimeters from the anterior margin of the tibial plateau was evaluated, there was no significant difference between the two techniques $(\mathrm{p}>0.05)$. In relation to the position of the tibial tunnel measured as a percentage of the length of the tibial plate, it was observed that there was a significant difference in the mean positioning between the two techniques $(\mathrm{p}<0.05)$.

\section{DISCUSSION}

Correct positioning of the tibial and femoral tunnels is one of the crucial points for achieving good results from ACL reconstruction ${ }^{19}$. Studies have demonstrated that incorrect positioning of the tunnels in the coronal and sagittal planes causes complications that modify the clinical results ${ }^{(6,7,12,16,17,20)}$, as well as being the commonest cause of lack of success in ACL reconstructions ${ }^{(21)}$.

Several methods are currently used for assessing the positioning of the bone tunnels during or after ACL reconstruction. Traditionally, the methods of Harner et $\mathrm{al}^{(16)}$ and Aglietti et $\mathrm{l}^{(17)}$ have been used to assess femoral tunnel positioning on lateral-view radiographs, even though the inter-observer differences are statistically significant ${ }^{(8,16,17)}$. Other authors have used the position of the interference screw and methods for identifying areas that are isometric, as references for assessing the tunnel positions ${ }^{(22)}$. This variety of methods makes comparisons difficult between the various studies that exist in the literature, because of the nonexistence of any method for which unanimity has been achieved.

Good et $\mathrm{al}^{(23)}$ studied the radiological location of the native ACL in cadavers and determined that the 
center of origin of the ligament in the femur was seen on lateral-view radiographs at a mean of $66 \%$ of the anterior limit of the Blumensaat line, and that the tibial insertion was located at the boundary between the anterior and middle thirds of the tibial plateau. Also using lateral-view radiographs, Khalfayan et $\mathrm{al}^{(6)}$ observed that there was a significant relationship between the orientation of the tunnels and the final clinical result from the reconstruction.

When the femoral tunnel is analyzed, positioning that is more vertical in the coronal plane may cause the graft to impact on the lateral part of the posterior cruciate ligament, thus generating loss of flexion and also increasing the anterior weakness ${ }^{(12,24)}$. The methods used in the present study only assessed the positioning in the sagittal plane. Anteriorized positioning of the femoral tunnel in the sagittal plane causes excessive tension in the graft, thereby leading to deterioration of the biomechanical properties of the graft and leading to failure of the fixation and recurrent instability ${ }^{(12,24-26)}$.

According to Aglietti et $\mathrm{al}^{(17)}$, the femoral tunnel should be positioned at $65 \%$ of the sagittal diameter of the distal femur. According to Harner et $\mathrm{al}^{(16)}$, the ideal positioning of the femoral tunnel should be at approximately $80 \%$ of the anteroposterior length of the Blumensaat line.

In relation to the tibial tunnel, positioning that is greatly anteriorized in the sagittal plane causes the graft to impact against the intercondylar roof, thereby generating limitation of extension, increased anterior translation, joint effusion and anterior pain in the knee ${ }^{(12,27-30)}$. On the other hand, positioning of the tunnel in a very posterior region of the tibial plateau is associated with a greater graft tear rate and greater loss of flexion ${ }^{(31)}$.

In the sagittal plane, Stäubli and Rauschning ${ }^{(18)}$ observed that tibial tunnel locations at $43 \pm 4 \%$ of the anteroposterior length of the tibia or at a distance of 20 to $23.7 \mathrm{~mm}$ measured from the anterior margin of the tibia were related to better clinical scores. Lintner et $\mathrm{al}^{(32)}$ examined knees from cadavers and concluded that the center of the ACL insertion in the tibia was at around $40 \%$ of the anteroposterior diameter, from its anterior margin. Pinczewski et $\mathrm{al}^{(31)}$ highlighted the correlation between the placement of the tunnels and the clinical result after reconstruction and recommended that, in the sagittal plane, the tibial tunnel should be placed at around $48 \%$ of the anteroposterior length of the tibial plateau.

Andrade et $\mathrm{al}^{(33)}$ compared the position of the femoral isometric point in ten cases operated arthroscopically and in ten cases operated using the open method with a single anterior incision in accordance with the criteria of Melhorn \& Henning. These authors did not find any statistically significant difference, but recommended the arthroscopic technique as safer for determining the femoral isometric point. In the present study, using the anteromedial portal, the analyses in Tables 1 to 3 show that the results found were close to those in the literature. However, a difference between the two techniques was found regarding the positioning of the femoral tunnel, such that the arthroscopic method showed greater precision for positioning the tunnel, and this difference was statistically significant.

In relation to the tibial tunnel, we also observed differences between the two techniques, but with divergent results regarding statistical significance, according to the type of measurement used. When absolute measurements in millimeters were used, there was no statistically significant difference between the techniques, despite the greater precision of the arthroscopic technique. On the other hand, when relative values were used, i.e. the percentage of the total length of the tibial plateau, the arthroscopic technique was also shown to be more precise and it came closer to the recommendations of Stäubli and Rauschning ${ }^{(18)}$. In this case, there was statistical significance between the two techniques. In relation to both the femoral tunnel and the tibial tunnel, there was a tendency to construct the bone tunnel more anteriorly in the sagittal plane when the open technique was used.

\section{CONCLUSION}

Through radiological analysis on knees that underwent ACL reconstruction, it was observed that the positioning of the bone tunnels (both femoral and tibial) was done in a more precise manner when the surgery was performed arthroscopically, in comparison with the open route. 


\section{REFERENCES}

1. Albright JC, Carpenter JE, Graf BK, Richmond JC. Knee and leg: Soft tissue trauma. In: Beaty JH, editor. Orthopaedic Knowledge Update 6. Rosemont, IL: AAOS; 1999. p. 533-59.

2. Gillquist J. Repair and reconstruction of the ACL: is it good enough? Arthroscopy. 1993;9(1):68-71.

3. Freedman KB, D'Amato MJ, Nedeff DD, Kaz A, Bach BR Jr. Arthroscopic anterior cruciate ligament reconstruction: a metaanalysis comparing patellar tendon and hamstring tendon autografts. Am J Sports Med. 2003;31(1):2-11.

4. Wetzler MJ, Bartolozzi AR, Gillespie MJ: Revision anterior cruciate ligament reconstruction. Oper Tech Orthop. 1996;6:181-9.

5. Yu J, Garret WE. Femoral tunnel placement in anterior cruciate ligament reconstruction. Oper Tech Sports Med. 2006;14(1):45-9.

6. Khalfayan EE, Sharkey PF, Alexander AH, Bruckner JD, Bynum EB. The relationship between tunnel placement and clinical results after anterior cruciate ligament reconstruction. Am J Sports Med. 1996;24(3):335-41.

7. Chhabra A, Diduch DR, Blessey PB, Miller MD. Recreating an acceptable angle of the tibial tunnel in the coronal plane in anterior cruciate ligament reconstruction using external landmarks. Arthroscopy. 2004;20(3):328-30.

8. Klos TV, Harman MK, Habets RJ, Devilee RJ, Banks SA. Locating femoral graft placement from lateral radiographs in anterior cruciate ligament reconstruction: a comparison of 3 methods of measuring radiographic images. Arthroscopy. 2000;16(5):499-504.

9. Topliss $C$, Webb J. An audit of tunnel position in anterior cruciate ligament reconstruction. Knee. 2001;8(1):59-63.

10. Hame SL, Markolf KL, Hunter DM, Oakes DA, Zoric B. Effects of notchplasty and femoral tunnel position on excursion patterns of an anterior cruciate ligament graft. Arthroscopy. 2003;19(4):340-5.

11. Sommer C, Friederich NF, Müller W. Improperly placed anterior cruciate ligament grafts: correlation between radiological parameters and clinical results. Knee Surg Sports Traumatol Arthrosc. 2000;8(4):207-13.

12. Buzzi R, Zaccherotti G, Giron F, Aglietti P. The relationship between the intercondylar roof and the tibial plateau with the knee in extension: relevance for tibial tunnel placement in anterior cruciate ligament reconstruction. Arthroscopy. 1999;15(6):625-31.

13. Raab DJ, Fischer DA, Smith JP, Markman AW, Steubs JA Comparison of arthroscopic and open reconstruction of the anterior cruciate ligament. Early results. Am J Sports Med. 1993;21(5):680-3.

14. Bernard M, Ristanis S, Chouliaras V, Paessler H, Georgoulis A. The anteromedial portal for anterior cruciate ligament reconstruction. In: Prodromos $\mathrm{CC}$, editor. The anterior cruciate ligament. Reconstruction and basic science. Philadelphia: Saunders Elsevier; 2008. p. 129-33.

15. Cameron SE, Wilson W, St Pierre P. A prospective, randomized comparison of open vs arthroscopically assisted ACL reconstruction. Orthopedics. 1995;18(3):249-52.

16. Harner $\mathrm{CD}$, Marks PH, Fu FH, Irrgang JJ, Silby MB, Mengato R. Anterior cruciate ligament reconstruction: endoscopic versus two-incision technique. Arthroscopy. 1994;10(5):502-12.

17. Aglietti P, Zaccherotti G, Menchetti PP, De Biase P. A comparison of clinical and radiological parameters with two arthroscopic techniques for anterior cruciate ligament reconstruction. Knee Surg Sports Traumatol Arthrosc. 1995;3(1):2-8.
18. Stäubli HU, Rauschning W. Tibial attachment area of the anterior cruciate ligament in the extended knee position. Anatomy and cryosections in vitro complemented by magnetic resonance arthrography in vivo. Knee Surg Sports Traumatol Arthrosc. 1994;2(3):138-46.

19. O'Meara PM, O'Brien WR, Henning CE. Anterior cruciate ligament reconstruction stability with continuous passive motion. The role of isometric graft placement. Clin Orthop Relat Res. 1992;(277):201-9.

20. Brandsson S, Karlsson J, Swärd L, Kartus J, Eriksson BI, Kärrholm J. Kinematics and laxity of the knee joint after anterior cruciate ligament reconstruction: pre- and postoperative radiostereometric studies. Am J Sports Med. 2002;30(3):361-7.

21. Behrend H, Stutz G, Kessler MA, Rukavina A, Giesinger K, Kuster MS. Tunnel placement in anterior cruciate ligament $(A C L)$ reconstruction: quality control in a teaching hospital. Knee Surg Sports Traumatol Arthrosc. 2006;14(11):1159-65.

22. Hefzy MS, Grood ES, Noyes FR. Factors affecting the region of most isometric femoral attachments. Part II: The anterior cruciate ligament. Am J Sports Med. 1989;17(2):208-16.

23. Good L, Odensten M, Gillquist J. Sagittal knee stability after anterior cruciate ligament reconstruction with a patellar tendon strip. A two-year follow-up study. Am J Sports Med. 1994;22(4):518-23.

24. Watanabe BM, Howell SM. Arthroscopic findings associated with roof impingement of an anterior cruciate ligament graft. Am J Sports Med. 1995;23(5):616-25.

25. Howell SM, Gittins ME, Gottlieb JE, Traina SM, Zoellner TM. The relationship between the angle of the tibial tunnel in the coronal plane and loss of flexion and anterior laxity after anterior cruciate ligament reconstruction. Am J Sports Med. 2001;29(5):567-74.

26. Lemos MJ, Albert J, Simon T, Jackson DW. Radiographic analysis of femoral interference screw placement during $A C L$ reconstruction: endoscopic versus open technique. Arthroscopy. 1993;9(2):154-8.

27. Howell SM, Clark JA, Farley TE. A rationale for predicting anterior cruciate graft impingement by the intercondylar roof. A magnetic resonance imaging study. Am J Sports Med. 1991;19(3):276-82.

28. Howell SM. Principles for placing the tibial tunnel and avoiding roof impingement during reconstruction of a torn anterior cruciate ligament. Knee Surg Sports Traumatol Arthrosc. 1998;6(Suppl 1):S49-55.

29. Howell SM, Clark JA. Tibial tunnel placement in anterior cruciate ligament reconstructions and graft impingement. Clin Orthop Relat Res. 1992;(283):187-95.

30. Yamamoto H, Ishibashi T, Muneta T, Furuya K, Mizuta T. Effusions after anterior cruciate ligament reconstruction using the ligament augmentation device. Arthroscopy. 1992;8(3):305-10.

31. Pinczewski LA, Salmon LJ, Jackson WF, von Bormann RB, Haslam PG, Tashiro S. Radiological landmarks for placement of the tunnels in single-bundle reconstruction of the anterior cruciate ligament. J Bone Joint Surg Br. 2008;90(2):172-9.

32. Lintner DM, Dewitt SE, Moseley JB. Radiographic evaluation of native anterior cruciate ligament attachments and graft placement for reconstruction. A cadaveric study. Am J Sports Med. 1996;24(1):72-8.

33. Andrade MAP, Carvalho Júnior LH. Reconstrução do LCA: ponto isométrico femoral Comparação entre as técnicas artroscópica e aberta. Rev Bras Ortop 1996;31(4):289-91. 